\title{
Transformational change: nurses substituting for ophthalmologists for intravitreal injections - a quality-improvement report
}

This article was published in the following Dove Press journal:

Clinical Ophthalmology

I5 April 2014

Number of times this article has been viewed

\author{
Monica M Michelotti ${ }^{1}$ \\ Salwa Abugreen ${ }^{2}$ \\ Simon P Kelly' \\ Jiten Morarji' \\ Debra Myerscough ${ }^{2}$ \\ Tina Boddie ${ }^{2}$ \\ Ann Haughton' \\ Natalie Nixon ${ }^{2}$ \\ Brenda Mason' \\ Evangelos Sioras' \\ 'Ophthalmology Department, Royal \\ Bolton Hospital NHS Foundation \\ Trust, Bolton, UK; ${ }^{2}$ Ophthalmology \\ Department, East Lancashire NHS \\ Trust, Blackburn, UK
}

Correspondence: Simon P Kelly

Ophthalmology Department,

Royal Bolton Hospital NHS Foundation

Trust, Minerva Road, Farnworth,

Bolton BL4 OJR, UK

Tel +44 I204390694

Email simonkelly@nhs.net
Background: The dramatic increase in need for anti-vascular endothelial growth factor (anti-VEGF) intravitreal therapy in the treatment of retinal disease and the absence of an equivalent increase in ophthalmologists to undertake such intravitreal injections created a patient-safety risk. Timing of intravitreal therapy (IVT) is critical to prevent vision loss and local clinics lacked capacity to treat patients appropriately. We aimed to improve capacity for IVT by nurse injections.

Materials and methods: A multidisciplinary prospective service-improvement process was undertaken at two adjacent general hospitals in the northwest of England. IVT injections by nurses were a principal component of solution development. After we had obtained appropriate institutional approval, experienced ophthalmic nurses were trained, supervised, and assessed to undertake IVT. Ophthalmologists directly supervised the first 200 injections, and a retina specialist was always on site.

Results: Nurses undertook 3,355 intravitreal injections between June 2012 and November 2013 , with minor adverse events ( $0.3 \%$ subconjunctival hemorrhage and corneal abrasion). There were no patient complaints at either hospital.

Conclusion: Experienced ophthalmic nurses quickly learned how to perform such injections safely. IVT by nurses was well accepted by patients and staff. Hospital A trained three nurses sequentially for improved flexibility in scheduling. Novel use of appropriately trained nonmedical staff can improve efficiency and access in an overburdened service with time-sensitive disease. Retinal assessment was undertaken by ophthalmologists only. Improved access to IVT is important, as treatment with anti-VEGF therapy reduces blindness at population levels.

Keywords: ophthalmology, retina, age-related macular degeneration, nurse, transformation, extended roles

\section{Introduction and context \\ Problem}

Age-related macular degeneration (AMD) is the leading cause of blindness in the developed world. ${ }^{1}$ The incidence and prevalence of AMD are increasing as the population ages and life expectancy improves. The recent development of intravitreal anti-vascular endothelial growth factor (anti-VEGF) therapy has presented a major breakthrough in the care of patients with wet or neovascular AMD (n-AMD). Approximately $41 \%$ of patients with such wet AMD experience severe loss of vision (more than six lines) within 3 years if not treated. ${ }^{2}$ Vision can usually be restored or maintained if treated in a timely manner. The National Institute for Health and Care Excellence (NICE) thus approved the anti-VEGF agent ranibizumab (Lucentis ${ }^{\circledR}$; Novartis, Basel, Switzerland) 
for wet-AMD patients for National Health Service (NHS) care in August 2008. ${ }^{3}$ The further development of antiVEGF agents and recent approvals by NICE for extended indications are also relevant for other major blinding retinal disorders. ${ }^{4-7}$

Anti-VEGF injections must be given on a regular basis, often monthly, and require regular monitoring to achieve effective clinical outcomes. Ophthalmology is a high-volume service, and 6,485,109 ophthalmology outpatient visits were undertaken in NHS care in England in 2011-2012. ${ }^{8}$ Based on real-world experience, Keenan et al estimated that 26,850 new-incident eyes require intravitreal therapy (IVT) for n-AMD per annum in the UK. ${ }^{9}$ There has been an exponential rise in IVT undertaken in the UK since the NICE approval of ranibizumab for wet AMD in 2008. This rapid expansion in such medical retina care and rise in IVT injections is putting significant pressures on NHS ophthalmology departments and finances. ${ }^{10,11}$ Untreated visual impairment can have a huge impact on independence and quality of life for such patients. ${ }^{12}$ This is also important at a societal level, as visual impairment was associated with costs of $£ 22$ billion in 2008 in the UK. ${ }^{13}$

In a review of patient-safety incidents related to antiVEGF medication use, as reported to the National Patient Safety Agency, delay in treatment or assessment was the principal patient-safety incident reported in England and Wales. ${ }^{14}$ In practice, the ideal care of patients undergoing anti-VEGF IVT is to see and treat such patients in a regular, ideally monthly, "one-stop," one-visit service, wherein the intravitreal injection is given on the same day of decision to treat. A one-stop service is usually most convenient to patients.

Various service-improvement initiatives have been undertaken in UK ophthalmology departments in an attempt to address capacity for n-AMD patient treatment, and were collated in Action on AMD. ${ }^{15}$ However, the innovations within Action on AMD did not include nurse injectors. Of relevance, there are fewer specialists in ophthalmology in the UK, pro rata, than in any other European Union economy. ${ }^{16}$ Ophthalmology in the UK has embraced modernization of staff roles and quality improvement, most notably within cataract care. ${ }^{17}$ Extended roles for nurses have been developed across many areas of NHS care, and are part of a wider expansion of ophthalmic nursing. ${ }^{18}$ Extended nurse roles within ophthalmic care, including substituting for ophthalmic surgeons in nurse yttrium aluminum garnet laser capsulotomy treatment, cataract clinic both pre- and postoperative assessment, and glaucoma clinic and nurse chalazion surgery, have occurred, and these chime with the widening of advanced nursing practices. ${ }^{19-21}$

\section{Context}

The East Lancashire Hospitals NHS Trust and the Royal Bolton Hospital NHS Foundation Trust are neighboring provincial district general hospitals in Lancashire located in the northwest of England. The East Lancashire Hospitals Trust (ELHT) serves a population of $\sim 770,000$ residents, and Royal Bolton Hospital (RBH) serves a population of $\sim 350,000$ residents as both hospitals receive retinal patients from surrounding districts. Both hospitals undertake the majority of NHS-funded treatment for general ophthalmic care, including medical retina care, in their respective catchment areas. IVTs have the potential for serious vision-threatening adverse events, including endophthalmitis, retinal detachment, and intraocular bleeding. At the time, both the Royal College of Ophthalmologists and the American Academy of Ophthalmology recommended IVT anti-VEGF medications should only be administered by an ophthalmologist. ${ }^{22,23}$ Furthermore the summary of product characteristics (SmPC) of anti-VEGF medications states that the medication should only "be administered by a qualified ophthalmologist experienced in intravitreal injections." ${ }^{24}$ However, in our opinion, experienced ophthalmic nurses had many of the skills for undertaking IVT injections under local anesthesia, such as excellent sterile-to-touch technique and good patient-comfort skills. In our experience and opinion, the technique of IVT is straightforward. There were no publications on IVT injections by nonmedical staff until 2013. The ELHT provided a patient-satisfaction presentation on this topic at the Oxford Ophthalmological Congress in 2013. Descriptions of IVT services were presented at the 2013 Royal College of Ophthalmologists Annual Congress from one NHS district hospital (Exeter) and a London ophthalmic teaching hospital (Moorfields). The only publication at the time of writing is a service evaluation of initiating nurse IVT from Sunderland, UK and a recent practical handbook. ${ }^{25,26} \mathrm{We}$ are not aware of any literature from outside the UK on nurse IVT. We are aware from personal contacts that nurse IVT is being undertaken in some clinics in Spain and Denmark.

\section{Staffing}

There are limited consultant medical retinal specialists based at each hospital (SA, SPK, ES). Both hospitals are involved in ophthalmology higher surgical training. Both hospital ophthalmic departments had previously developed nurse practitioners and extended roles in house, including glaucoma 
care, cataract evaluation, and undertaking chalazion and oculoplastic surgery. The ophthalmic departments of both hospitals were working at full capacity prior to the NICE technology approval for n-AMD patient care in 2008, when the rollout of ranibizumab IVT for wet AMD occurred. ${ }^{3}$

A shortage of middle-grade nonconsultant nontraining specialist doctors (known as Staff and Associate Specialist [SAS]-grade doctors) in the UK has emerged following changes to immigration rules. ${ }^{27}$ The revised training curriculum from the Royal College of Ophthalmologists does not support the use of ophthalmology trainees for dedicated service provision. ${ }^{28}$

Training opportunities for ophthalmology higher surgical trainees in dedicated anti-VEGF injection sessions are limited, as the activity is considered straightforward. Therefore, both hospitals lacked sufficient numbers of ophthalmology medical staff to meet the requirement for the modern anti-VEGF era. Specifically, hospital A relied on a single consultant supported by intermediate-grade SAS ophthalmologists to undertake IVT and supporting optometry staff to provide onestop service. Additional sessions for review were required to cope with rising demand. Hospital B relied on existing consultants undertaking pro bono extra sessions out of hours in operating theaters for injections and locum consultant ophthalmologists at $£ 500$ per session to supplement the antiVEGF injection service. Neither was sustainable: the costs of such locum/agency work were significant, and the availability of locum ophthalmologists of quality was problematic. Injections in the operating theaters were putting pressure on ophthalmology operating facilities and on surgical staff. Furthermore, frequently patients attended for an assessment visit wherein active retinal disease was determined and antiVEGF treatment indicated; however, the patient would have to be scheduled to attend at a further date for the injection treatment (two-stop service) at hospital B.

\section{Solution development Assessment of problem}

With the granting of NICE approval for n-AMD treatment, both hospitals struggled to cope with the extra demand for retinal patient care that was placed on ophthalmology services. The ophthalmology departments were coping with multiple clinic visits for AMD patient assessment, eg, initial clinic visit, visit for refraction and visual acuity, retinal clinic appointment, assessment visit for retinal imaging (fluorescein angiography and optical coherence tomography examinations), and injection visit, in what is a time-sensitive condition. The 2009 Royal College of Ophthalmologists guidelines recommended IVT be given within 1 week of diagnosis of n-AMD. ${ }^{29}$ It was thought that a one-stop or two-stop visit would be much more productive and efficient and importantly less demanding on patients while improving compliance with college guidelines and clinical outcomes. Furthermore, when IVT anti-VEGF is not given as scheduled, irretrievable loss of vision may occur, with major impacts on patient quality of life and a potential medicolegal risk to providers. However, the absence of an equivalent increase in ophthalmologists to provide IVT resulted in clinics being overbooked, with increased waiting time for IVT, and additionally had an adverse impact on operating theater capacity for other ophthalmic surgical services. This was deemed an important patient-safety and financial risk problem for ophthalmology services at both NHS trusts.

\section{Results \\ Redesign and strategies for change}

In hospital A, the IVT capacity issue was discussed by the macular services multidisciplinary team and at directorate level. All were agreed on training nonmedical staff to undertake IVT injections to free up medical staff to review new and follow-up AMD patients. This was approved by the surgical directorate and governance committee in February 2012. At hospital B, a service-improvement event for ophthalmology multidisciplinary team staff was conducted in 2010. Hospital A commissioned a clean room for IVT injections in 2007. A dedicated clean room for IVT injections was commissioned at hospital B by conversion of existing facilities and with funding from a legacy in 2012. IVT injection by experienced ophthalmic nurses was envisaged as a component of solution development at both hospitals. Other solutions included extended roles for in-house hospital optometrists and telemedicine triage in retinal care at hospital B, as outlined in the Action on AMD review. ${ }^{15,30}$

The service innovation proposed was that experienced ophthalmic nurses (TB, AH, DM, and NN) undertake IVT injections instead of ophthalmologists. As such intervention was not then in line with either of the then Royal College of Ophthalmologists guidance or ranibizumab SmPC, such a controversial proposal required submission to the hospital board level governance committee. Institutional approval was given at director level in both hospitals.

Experienced ophthalmic nurses were then trained, supervised, and assessed to undertake intravitreal injections at the request of an experienced ophthalmologist. In hospital A, the experienced nurse practitioner had as scrub nurse observed the IVT procedure being undertaken 1,560 times by 
ophthalmic medical staff prior to undertaking injections. In hospital B, the experienced nurse practitioner as scrub nurse had observed the procedure being undertaken $\sim 1,000$ times by ophthalmic medical staff prior to her undertaking injections. When a novel disposable polycarbonate device (InVitria; FCI Surgical Devices, Paris, France $)^{31,32}$ became available for IVT injections, local nurses expressed more interest in undertaking IVT. An audit of 200 patients undergoing IVT with this novel device was undertaken at hospital A. We found this device was patient-friendly, cost-effective, and safe.

Patients were informed that the IVT was being undertaken by a nurse practitioner, were offered choice of doctor or nurse injection, and could decline the nurse injection and request that the doctor perform the injection. The disposable IVT speculum device was used by nurse injectors at both sites. IVT injections were only undertaken by nurses when the need for anti-VEGF treatment was determined with the patient by an experienced retinal specialist. At each clinic visit, visual acuity measurement, optical coherence tomography imaging, and clinical examination was conducted to facilitate the ophthalmologist's decision-making process.

The first 200 injections undertaken by nurse practitioners were directly supervised by an ophthalmic specialist at each hospital. A retina specialist was available on site to provide guidance at all times. The retinal specialists at both hospitals then directly assessed the nurse undertaking the IVT injection, and confirmed that the nurse had suitable levels of knowledge and skills to undertake such treatment. Once this training process was completed and relevant paperwork signed off by the hospital trust, the nurse practitioners were deemed in a position to undertake independent IVT injection lists without medical staff being present in the injection room. Hospital A initiated this innovation 12 months prior to hospital B. Staff from hospital B visited hospital A to understand the processes required and lessons learned prior to start-up at hospital B. This quality-improvement report is a service evaluation. Service evaluation is conducted to judge current care, and differs from clinical research or clinical audit in that no randomization or comparison to a standard is undertaken. ${ }^{33}$

\section{Measurement of improvement}

A prospective record of all injections performed by the nurse injectors, including descriptive reporting of adverse events and complications at both hospitals, was undertaken. These were audited, and outcomes were discussed at multidisciplinary clinical governance meetings.

Three senior and experienced ophthalmic nurses under- take all the injection clinics in hospital A and which commenced in
June 2012. Two (TB and DM) have over 20 years ophthalmic experience, including extended periods as ophthalmic theater scrub nurses, including in vitreoretinal surgery. Staff from hospital B undertook study visits to hospital A. In May 2013, one senior nurse $(\mathrm{AH})$ in hospital B commenced performing IVT injections in hospital B. Nurse IVT sessions run parallel to consultant/SAS doctor clinics. To date, no patient has declined nurse injection at either hospital. As of November 1 , 2013, the nurses had performed 3,355 IVT injections at the two hospitals, of which $98 \%$ were for wet AMD. There have been no formal or informal patient complaints at either hospital. Formal patient satisfaction surveys are ongoing.

\section{Effects of change}

\section{Process outcome}

Hospital A trained three nurses sequentially, which allows for improved flexibility and increased physician time and time in scheduling clinics. Hospital B gained insights from the earlier rollout in IVT in hospital A. In hospital A, the nurse injectors are now the sole administrators of all IVT injections, while in the other hospital the nurse performs $40 \%$ of such injections. The nurse at hospital B has the option of creating additional injection sessions as needed to meet patient demand or medical staff shortage. A further nurse at hospital B is undergoing training in the IVT technique. Nurse IVT injecting was well received by patients and staff at both hospitals. In hospital B, locum/agency medical staffing was previously $\sim £ 500$ per session and required three such sessions per week. Currently, there is one locum/agency medical staffing session per week, resulting in a gross saving of $£ 1,000$ per week on locum medical staffing costs. The innovation of nurse injecting has freed up retinal specialists at both hospitals to concentrate on the assessment and diagnosis of patients with retinal disease, thus allowing more patients to be assessed in a timely fashion. Patients continue to be evaluated by an ophthalmologist or optometrist at all visits, unless it is an injection visit only. The nurses do not participate in the technical diagnosis of retinal diseases.

\section{Patient-centered outcomes}

This service improvement has reduced patient waiting time and improved compliance with guidelines regarding antiVEGF treatment in both hospitals. Additionally, the new process has allowed for the creation of a one-stop visit at both hospitals. Hospital A is currently a principally one-stop service. The nurse IVT process has freed ophthalmic medical staff to review AMD patients within recommended guidelines. Furthermore, as patient visit times reduced with the rollout 
of the nurse-led injection service, patient flow within the ophthalmology service improved. As a result of better access to services, patient satisfaction - as evidenced by formal and informal feedback and reduction in complaints - improved. Hospital A received the "Best Clinical Macular Service in the UK" award from the Macular Society in 2012, while hospital B was a runner-up.

\section{Clinical outcomes}

Across the two hospitals, 3,355 nurse injections were performed up to November 1, 2013, with 12 minor adverse events (corneal abrasions, subconjunctival hemorrhage; rate $0.36 \%$ ). Adverse events were recorded prospectively. Importantly, there were no cases of serious adverse events (vision-threatening adverse events, such as endophthalmitis, retinal tear, retinal detachments, or vitreous hemorrhage). These clinical outcomes benchmark well with the safety signals from the key studies of ranibizumab and the national audit of endophthalmitis events following IVT undertaken by ophthalmologists in NHS care. ${ }^{34}$

Hospital A undertook an audit to assess patients' satisfaction comparing the standard injection technique with drape versus the novel InVitria device without drape. ${ }^{31}$ We asked 200 patients to complete a questionnaire comparing these two methods: $75 \%(n=150)$ preferred the InVitria device, $12 \%$ $(\mathrm{n}=24)$ preferred the standard IVT technique, and 13\% $(\mathrm{n}=26)$ had no preference; $12.5 \%(n=25)$ did not like a drape on their face, and another $12.5 \%$ of patients felt claustrophobic with the drape. No complication was observed with either technique in the audit sample. Our audit results reflect with the only publication accessing this device. ${ }^{32}$

When the nurse injection intervention was first rolled out, only ranibizumab was approved for IVT, and then only for n-AMD patients. In 2013, following NICE approval of ranibizumab for wider retinal indications and aflibercept for n-AMD, the nurse injection in both hospitals began to undertake IVT injections for expanded retinal disorders, as commissioned locally. This is relevant to future service provision, as we predict the expanded clinical indications will double the incident requirement for IVT injections in our catchment populations based on the estimates provided within each NICE guidance.

\section{Discussion}

\section{Lessons and messages}

Nonmedical staff can substitute for medical staff and improve efficiency and access by fulfilling unmet needs of patients in an overburdened service treating time-sensitive retinal disease. Appropriate training and supervision of such nonmedical staff is critical to safety. Problems encountered included obtaining approval for nurses to perform IVT injection, given opposition to nonmedical staff performing IVT injections and given the wording of the ranibizumab SmPC. In early 2013, Royal College of Ophthalmologists guidance on IVT was revised to include approval of appropriately trained nonmedical staff. ${ }^{35}$ There has not been any relaxation of the American Academy of Ophthalmology guidelines on IVT. $^{23}$ Any revision of the ranibizumab SmPC to include nurse/paramedical IVT injection will require application by the manufacturer and approval by the relevant medicinelicensing agency. Publication of clinical outcomes following IVT injections by nonmedical staff will be needed to support any such license revision.

The prevalence of $\mathrm{n}-\mathrm{AMD}$ is predicted to continue increasing over the next few decades in developed economies, with increasing strain on ophthalmic services predicted. ${ }^{36,37}$ Intravitreal anti-VEGF injections maintain vision for many patients with retinal disease. Experience with anti-VEGF is leading to a reduction of vision impairment attributable to n-AMD. This has been demonstrated in real-world outcomes in clinical audits in NHS eye clinics, and importantly in blindness registrations in the UK and internationally. ${ }^{14,38-42}$

As repeated dosing with anti-VEGF agents will remain the standard of care for key retinal vascular disorders for the foreseeable future, increasing numbers of IVT injections are needed in most economies. Such injections by nursing staff were safe and well accepted by patients and staff in our facility and in other UK centers. Such staff role substitution can be considered a "disruptive innovation" contribution. ${ }^{43}$ Wider rollout of injections by non-medical staff will be critical to providing cost-effective and efficient care. Given a shortage of ophthalmologists in many economies and an increasing prevalence of such treatable and blinding disease, IVT injections by nonmedical staff represent a potential quality improvement within a multifaceted strategy of service improvement in high-volume time-sensitive retinal diseases.

\section{Acknowledgments}

We are most grateful to Mr W Amoaku, consultant ophthalmic surgeon, and to Dr M Fotaki, public health specialist, for comments on the manuscript.

\section{Disclosure}

SPK has acted as a consultant and speaker for Novartis and a consultant for Alimera and Bayer in the last 24 months. $\mathrm{SA}, \mathrm{SPK}, \mathrm{DM}, \mathrm{TB}$, and NN have received conference travel 
support from Novartis. ES has received conference travel support from Alcon and Novartis. Royal Bolton Hospital is involved in research supported by Allergan, Bayer, and Novartis. The East Lancashire Hospital Trust is involved in research supported by Novartis. The other authors have no conflicts of interest in this work.

\section{References}

1. Bressler NM. Age-related macular degeneration is the leading cause of blindness. . . JAMA. 2004;291:1900-1901.

2. Wong TY, Chakravarthy U, Klein R, et al. The natural history and prognosis of neovascular age-related macular degeneration: a systematic review of the literature and meta-analysis. Ophthalmology. 2008;115:116-126.

3. National Institute for Health and Clinical Excellence. Ranibizumab and Pegaptanib for the Treatment of Age-Related Macular Degeneration. London: NICE; 2008. Available from: http://www.nice.org.uk/ nicemedia/live/12057/41719/41719.pdf. Accessed February 12, 2014.

4. National Institute for Health and Care Excellence. Ranibizumab for Diabetic Macular Odema (Rapid Review of Technology Appraisal Guidance 237). London: NICE; 2013. Available from: http://www.nice.org.uk/ nicemedia/live/14082/62873/62873.pdf. Accessed February 12, 2014.

5. National Institute for Health and Care Excellence. Ranibizumab for Treating Visual Impairment Caused by Macular Oedema Secondary to Retinal Vein Occlusion. London: NICE; 2013. Available from: http:// www.nice.org.uk/nicemedia/live/14169/63851/63851.pdf. Accessed February 12, 2014.

6. National Institute for Health and Care Excellence. Ranibizumab for Treating Choroidal Neovascularisation Associated with Pathological Myopia. London: NICE; 2013. Available from: http:/www.nice.org.uk/ nicemedia/live/14305/65827/65827.pdf. Accessed February 12, 2014.

7. National Institute for Health and Care Excellence. Aflibercept Solution for Injection for Treating Wet Age-Related Macular Degeneration. London: NICE; 2013. Available from: http://www.nice.org.uk/nicemedia/ live/14227/64572/64572.pdf. Accessed February 12, 2014.

8. Health and Social Care Information Centre. Hospital Episode Statistics: Hospital Outpatient Activity 2011-12 - Summary Report. Leeds: HSCIC; 2012. Available from: https://catalogue.ic.nhs.uk/publications/ hospital/outpatients/hosp-outp-acti-11-12/hosp-outp-acti-11-12-summrepo-rep.pdf. Accessed November 22, 2013.

9. Keenan TDL, Kelly SP, Sallam A, Mohamed Q, Tufail A, Johnston RL. Incidence and baseline clinical characteristics of treated neovascular age-related macular degeneration in a well-defined region of the UK. Br J Ophthalmol. 2013;97:1168-1172.

10. Keenan TD, Wotton CJ, Golacre MJ. Trends over time and geographical variation in rates of intravitreal injections in England. Br J Ophthalmol. 2012;96:413-418.

11. Royal College of Ophthalmologists. Maximising Capacity in AMD Services. London: Royal College of Ophthalmologists; 2009.

12. Mitchell J, Bradley C. Quality of life in age-related macular degeneration: a review of the literature. Health Qual Life Outcomes. 2006;4:97.

13. Royal National Institute of Blind People. Future Sight Loss UK 1: Economic Impact of Partial Sight and Blindness in the UK Adult Population. London: RNIB; 2009. Available from: http://www.rnib.org. uk/aboutus/research/reports/otherresearch/pages/fsluk1.aspx. Accessed February 12, 2014.

14. Kelly SP, Barua A. A review of safety incidents in England and Wales for vascular endothelial growth factor inhibitor medications. Eye (Lond). 2011;26:710-716.

15. Amoaku W, Blakeney S, Freeman M, et al. Action on AMD. Optimising patient management: act now to ensure current and continual delivery of best possible patient care. Eye (Lond). 2012;26 Suppl 1: S2-S21.
16. European Union of Medical Specialists [website on the Internet]. Available from: http://www.uems.net. Accessed February 12, 2014.

17. Tey A, Grant B, Harbison D, Sutherland S, Kearns P, Sanders R. Redesign and modernisation of an NHS cataract service (Fife 1997-2004): multifaceted approach. BMJ. 2007;334:148-152.

18. Marsden J. Advanced practice in nursing, a United Kingdom and international perspective. Insight. 2013;38:16-18.

19. Forbes M. Bursting the bubblewrap: evolution and monitoring of nurse-performed Nd:YAG laser capsulotomy service. Int J Ophthalmic Pract. 2013;4:157-162.

20. Jackson TL, Beun L. A prospective study of cost, patient satisfaction, and outcome of treatment of chalazion by medical and nursing staff. Br J Ophthalmol. 2000;84:782-785.

21. Royal College of Nursing. Maxi Nurses: Nurses Working in Advanced and Extended Roles Promoting and Developing Patient-Centred Health Care. Cardiff: RCN; 2005. Available from: http://www.ren.org.uk/_data/ assets/pdf_file/0004/78646/002511.pdf. Accessed February 12, 2014.

22. Amoaku W, Pearce I, Browning A. Guidelines for Intravitreal Injections Procedure. London: Royal College of Ophthalmologists; 2009. Available from: http://www.rcophth.ac.uk/core/core_picker/download. asp?id=167\&filetitle=Guidelines+for+Intravitreal+Injections + Procedu re+2009. Accessed February 12, 2014.

23. American Academy of Ophthalmology. Intravitreal injections: guidelines and technique. Available from: http://one.aao.org/ focalpointssnippetdetail.aspx?id=f759cd36-2047-4608-a 78c9bbd42fa7cac. Accessed February 12, 2014.

24. Novartis. Summary of product characteristics: Lucentis $10 \mathrm{mg} / \mathrm{mL}$ solution for injection. Lucentis prescribing information. Available from: http://www.medicines.org.uk/emc/medicine/19409/SPC. Accessed February 12, 2014.

25. Varma D, Lunt D, Johnson P, Stanley S. A novel approach to expanding the role of nurses to deliver intravitreal injections for patients with age related macular degeneration. Int J Ophthalmic Pract. 2013;4 (2): 68-74.

26. Waqar S, Park JC, Cole MD. Intravitreal Injections: A Handbook for Ophthalmic Nurse Practitioners and Trainee Ophthalmologists. Singapore: World Scientific; 2014.

27. Rechel B, Dubois CA, McKee M. The Health Care Workforce in Europe: Learning from Experience. Trowbridge, UK: Cromwell; 2006.

28. Royal College of Ophthalmologists. Curriculum for ophthalmic surgical training. Available from: http://curriculum.rcophth.ac.uk/ost. Accessed February 12, 2014.

29. Royal College of Ophthalmologists. Guidelines on AMD treatment. 2009. The Royal College of Ophthalmologists, London.

30. Kelly SP, Wallwork I, Haider D, Qureshi K. Teleophthalmology with optical coherence tomography imaging in community optometry. Evaluation of a quality improvement for macular patients. Clin Ophthalmol. 2011;5:1673-1678.

31. FCI Surgical Devices. Intravitreal injections: InVitria pack. Available from: http://www.fciworldwide.com/index.php?1_idpa=67. Accessed February 12, 2014.

32. Ratnarajan G, Nath R, Appaswamy S, Watson SL. Intravitreal injections using a novel conjunctival mould: a comparison with a conventional technique. Br J Ophthalmol. 2013;97:395-397.

33. Health Research Authority. Defining Research. London: National Health Service; 2013. Available from: http://www.hra.nhs.uk/ documents/2013/09/defining-research.pdf. Accessed February 12, 2014.

34. Lyall DA, Tey A, Foot B, et al. Post-intravitreal anti-VEGF endophthalmitis in the United Kingdom: incidence, features, risk factors, and outcomes. Eye (Lond). 2012;26:1517-1526.

35. Royal College of Ophthalmologists. College statement on intra-ocular injections by non-medical health care professionals. 2013. Available from: http://www.rcophth.ac.uk/news.asp?itemid=1363\&itemTitle= College+Statement+on+intra-ocular+injections+by+non-medical+he alth + care + professionals \&section $=24 \&$ sectionTitle $=$ News. Accessed February 12, 2014. 
36. Minassian DC, Reidy A, Lightstone A, Desai P. Modelling the prevalence of age-related macular degeneration (2010-2020) in the UK: expected impact of anti-vascular endothelial growth factor (VEGF) therapy. $\mathrm{Br}$ J Ophthalmol. 2011;95:1433-1436.

37. Rein DB, Wittenborn JS, Zhang X, Honeycutt AA, Lesesne SB, Saaddine J. Forecasting age-related macular degeneration through the year 2050: the potential impact of new treatments. Arch Ophthalmol. 2009; $127: 533-540$.

38. Rostron E, McKibbin M. Visual impairment certification secondary to ARMD in Leeds, 2005-2010: is the incidence falling? Eye (Lond). 2012;26:933-936.

39. Cackett P, Borooah S, Gavin M, Oladiwura D, Swetha V, Jeganathan E. Intravitreal ranibizumab treatment of wet macular degeneration in SE Scotland - effect on blindness rates and 5 year follow up data. Poster presented at: Association for Research in Vision and Ophthalmology Annual Meeting; May 5-9, 2013; Seattle, WA.
40. Bloch SB, Larsen M, Munch IC. Incidence of legal blindness from age-related macular degeneration in Denmark: year 2000 to 2010. Am J Ophthalmol. 2012;153:209-213.

41. Skaat A, Chetrit A, Belkin M, Kinori M, Kalter-Leibovici O. Time trends in the incidence and causes of blindness in Israel. Am J Ophthalmol. 2012;153:214-221. e1.

42. Claessen H, Genz J, Bertram B, et al. Evidence for a considerable decrease in total and cause-specific incidences of blindness in Germany. Eur J Epidemiol. 2012;27:519-524.

43. Christensen CM, Grossman JH, Hwang J. The Innovator's Prescription: A Disruptive Solution for Health Care. New York: McGraw-Hill; 2009.
Clinical Ophthalmology

\section{Publish your work in this journal}

Clinical Ophthalmology is an international, peer-reviewed journal covering all subspecialties within ophthalmology. Key topics include: Optometry; Visual science; Pharmacology and drug therapy in eye diseases; Basic Sciences; Primary and Secondary eye care; Patien Safety and Quality of Care Improvements. This journal is indexed on

Submit your manuscript here: http://www.dovepress.com/clinical-ophthalmology-journal

\section{Dovepress}

PubMed Central and CAS, and is the official journal of The Society of Clinical Ophthalmology (SCO). The manuscript management system is completely online and includes a very quick and fair peer-review system, which is all easy to use. Visit http://www.dovepress.com/ testimonials.php to read real quotes from published authors. 